\title{
Maurício Da FaU
}

\author{
Júlio Roberto Katinsky
}

Maurício Nogueira Lima com Sacillotto e Waldemar Cordeiro, formam, dentro do movimento concretista, uma vertente especial, aquela mais comprometida com o espaço urbano.

Não é, pois, por acaso que uma parte da obra de Cordeiro se resolvesse em paisagismo, e Sacillotto, ao lado de suas telas planas, elaborasse objetos tridimensionais ou mesmo baixos-relevos, como querendo saltar de um espaço bidimensional do quadro para nosso espaço do cotidiano.

Mas seria exagero dizer que Maurício, por sua obra, é o que mais densamente acreditou em uma racionalidade da expressão como possibilidade comum a todos nós? Fato é que sua obra é a mais acessivel em nosso meio, enquanto leitura. E também, não por acaso, a mais difundida, ainda que não tenha sido feito o estudo crítico a que ele e seus companheiros fazem jus, sem desmerecer, muito ao contrário, o esforço analítico já realizado.

Sua obra enquanto pintor pode ser dividida em três partes: sua primeira adesão ao grupo "Ruptura" ainda estudante de arquitetura no Mackenzie, na qual, dentro dos rígidos cânones do "neoplasticismo" holândes ou do concretismo (enquanto corolário lógico da ideologia do Stijl), procurava dar vida à sua ambição de se integrar aos processos produtivos, pura e simplesmente "dissolvendo-se na vida"

Um segundo momento, talvez o mais rico de Waldemar Cordeiro, quando alguns concretistas confessaram em suas obras perplexidade perante a irrupção "anarcoestética" do movimento pop norte-americano. Mas o pop não foi para esses concretistas adesão passiva à moda, e sim um momento de reflexão sobre as funções da arte em uma sociedade moderna economicamente subdesenvolvida.

Um terceiro momento, para Maurício (e em parte para Sacillotto), quando houve um aparente recuo para posições neoconcretistas. Mas segundo meu juízo, esta apreciação não subsiste, pois o que houve foi uma reavaliação do concretismo, nāo naquilo que ele proclamava (fusão de arte com a vida), mas naquilo que ele efetivamente defendia (a arte na vida cotidiana). Essa última postura, mais moderna e que se nota pela rejeição de qualquer limitação pela cromática e pela ironia que vai dominar os quadros, tão claramente expressa no grande painel projetado para a praça São Bento, estabelece pela primeira vez uma expressão poética e, mesmo em alguns casos, onírica.

Enquanto escrevo estas linhas, contemplo os quadros que Mauricio me deu, de todas as suas fases, e é tendo todas em minha lembrança que penso nele como um mestre de tantos artistas, seus alunos na FAU, mas antes de tudo, um mestre fraterno que se impunha pela afetividade de um irmão mais velho. E é assim que eu o vejo hoje: sempre como o irmão mais velho que nunca tive. 


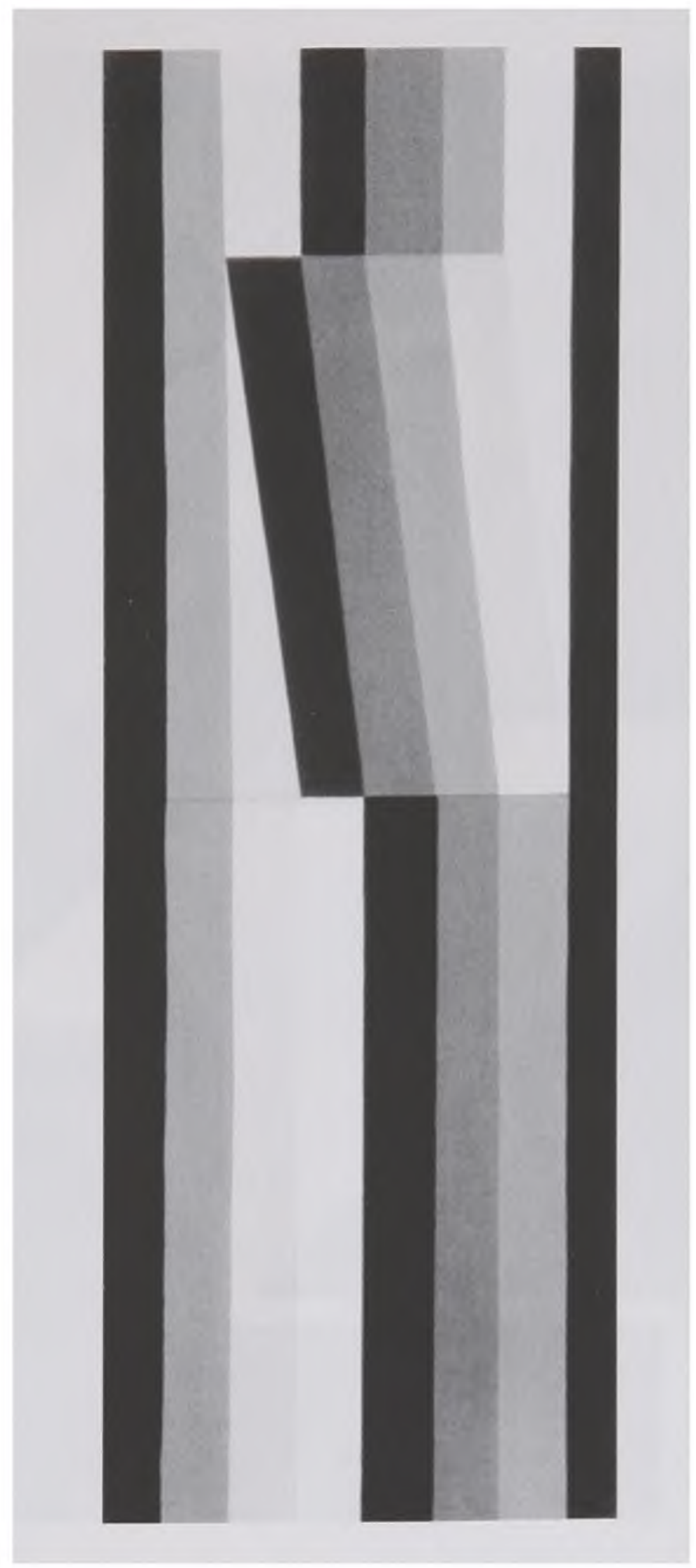

pós- $\mid \begin{gathered}\alpha \\ \alpha\end{gathered}$

Díptico Acrilico sobre tela - 1,40m x 0,50m 1978-1995 

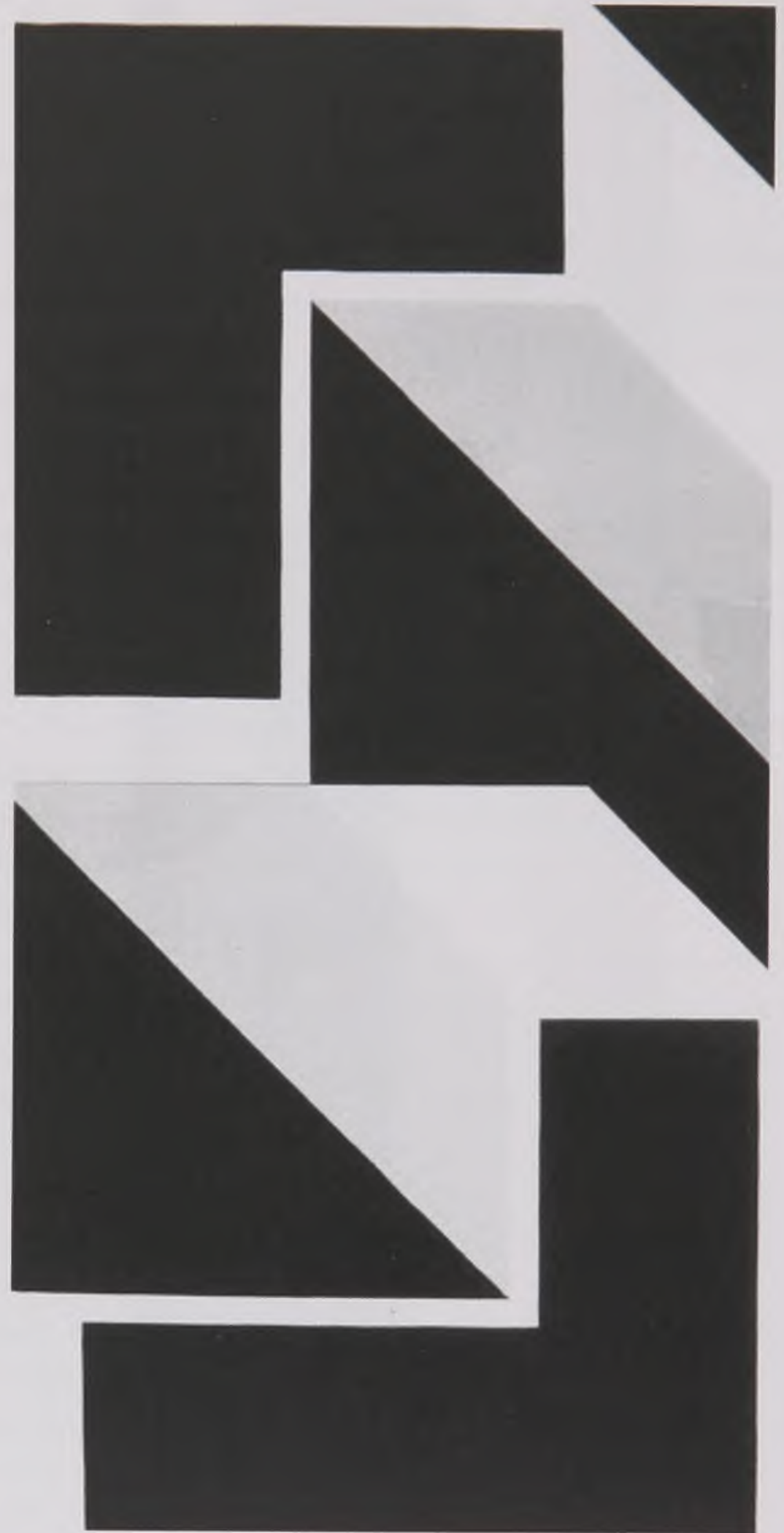

Díptico Acrilico sobre tela - 2,80m x 1,40m 1997 